\title{
Evaluation of Acacia Species as Honeybee Forage Potential
}

\author{
Dalip Kumar ${ }^{1}$, Vineeta Sharma ${ }^{2}$ \\ ${ }^{1}$ Associate Professor, Department of Zoology, PG GOVT. College for Girls, Sector-42, Chandigarh (160036) \\ ${ }^{2}$ Associate Professor, Department of Botany, PG GOVT. College for Girls, Sector-42, Chandigarh ( 160036)
}

\begin{abstract}
The comprehensive and extensive studies were made to work out the honey bee forage in different location of the city beautiful-Chandigarh as well as adjoining region. The present study reveals that different species of Acacia are the potential source of bee forage.The observations were made with respect of five species of Acaciaviz,; Acacia concinna (Wild.), Acacia nilotica ( L.), Acacia catechu(Roxb.) Willd., Acacia juliflora (Sw)Wild. and Acacia leucophloea( Roxb.)Willd.
\end{abstract}

Keywords: Acacia, Evaluation, BeeForage , Pollen, Nectar

\section{Material and Methods}

The determination of a plant as a honeybee plant was done through direct observation of foraging honeybee workers on its flowers. These observations were made during field trips, which lasted from dawn to dusk, organized periodically in all seasons. Only plants on which many foragers sustained foraging for nectar and pollen were recorded. Some of the plants were photographed with a digital camera. Direct observations were made with the help of Nikon Camera with configuration of DX AF-S NIKKOR 18-55mm. Occasionally, observations were also recorded with the help of Sony Xperia mobile Z1 and Sony camera 14.1 Mega Pixels. Extensive observations were recorded with respect to types of relevant species visited and feeding.

\section{Introduction}

Flowering plants and honeybees have a special relationship in which both are benefited from each other. As honeybees get food and in turn facilitate their pollination process. Honeybees visit flowers to collect pollen and nectar. Pollens are the principle source of protein and minerals which are essential for honeybee growth and development. Nectar is the carbohydrate portion of the honeybee's food and act as the raw material of honey (Abrol,1997 ). Standard honey yield mainly depends on the availability of flora, which provide nectar and pollens in copious quantity year around. So for maximum honey production it becomes imperative to establish a balanced bee forage system where there is adequate bee forge for large parts of the season but there are certain period of time during which the local bee forage is inadequate and such gaps can be filled with planting of suitable bee plants. The aim of the present study is to record the foraging activities of honeybee on different types of flowering plants in and around Chandigarh to identify the most important bee plants in different seasons and to include them while establishing a balanced bee foraging system.

The status of flowering plants whether they are major or minor was determined by the frequency and the number of honey bees visits.( Harugade and Chaphalkar ,2013).During foraging activities, honeybees identify and differentiate among various flowers using odors and both intensity and odor quality effect the ability of honeybee to discriminate between floral perfumes .B.monosperma plant was found to be indispensable for number of insects and birds species particularly honeybees ( Kumar,2015)for food .Foraging frequency for collection of forage depends upon type of flowers ( Prasad ,1983), type and quantity of flora. Rao and Suryanarayana ,1990; Rao,1991;Darshad et al,1992).It has been observed that Flowers are often accepted or rejected ultimately on the basis of their odors .

\section{Results and Discussions}

Chandigarh region is suitable for growing various multipurpose flora due to good degree of diversity in climatic conditions and temperature (Kohli ,et.al, 1994). There is diversity of flora in different seasons and honey bees visited these plants for pollen and nectar. Medicinal bee flora of a Chandigarh region enable beekeepers to utilize them at the maximum level, so that they can harvest a good yield of honey and other bee products in addition to effective pollination, which boosts crop yields ( Kumar, et. al,2015). Such knowledge on bee flora help in the effective management of bee colonies during such periods. The genus Acacia pays vital role as bee forage source .

Acacia concinna ( Figure 1)has been used traditionally for hair care and commonly use in Ayurvedic medicine and its extracts are used in natural shampoos and the tree is now grown commercially in India. The blooming period usually from March and April and it the excellent bee forage source - The workers bee visits each flowers for collection of nectar and pollen. The most active period for bee forage prevails between $8: 30$ to $12: 30 \mathrm{pm}$ and during this period worker bees collect the pollen. It has been observed that worker bee fed for 15-20 seconds during single visit .

Acacia nilotica ( Figure2)is popular as an agroforestry tree, either sown in lines $5 \mathrm{~m}$ apart in agricultural fields, or on field crop boundaries. Acacia nilotica is bright yellow flowers in round heads and is prolific, and can occur a number of times in a season The blooming period is October to December and March to April. The honeybee 


\section{International Journal of Science and Research (IJSR) \\ ISSN (Online): 2319-7064 \\ Index Copernicus Value (2013): 6.14 | Impact Factor (2014): 5.611}

worker basically visit the flowers for the purpose of pollen and fed for 20-30 seconds during single visit .

Acacia catechu( Figure 3) is a moderate size deciduous tree which grows on all kind of geological formations and soils. The blooming months are from March to April and during this phase it act as excellent source of nectar and pollen . The most active hours for collection of bee forage are between 7:00am to $1: 30 \mathrm{pm}$ and fed for 20 to 30 seconds during theparticular visit

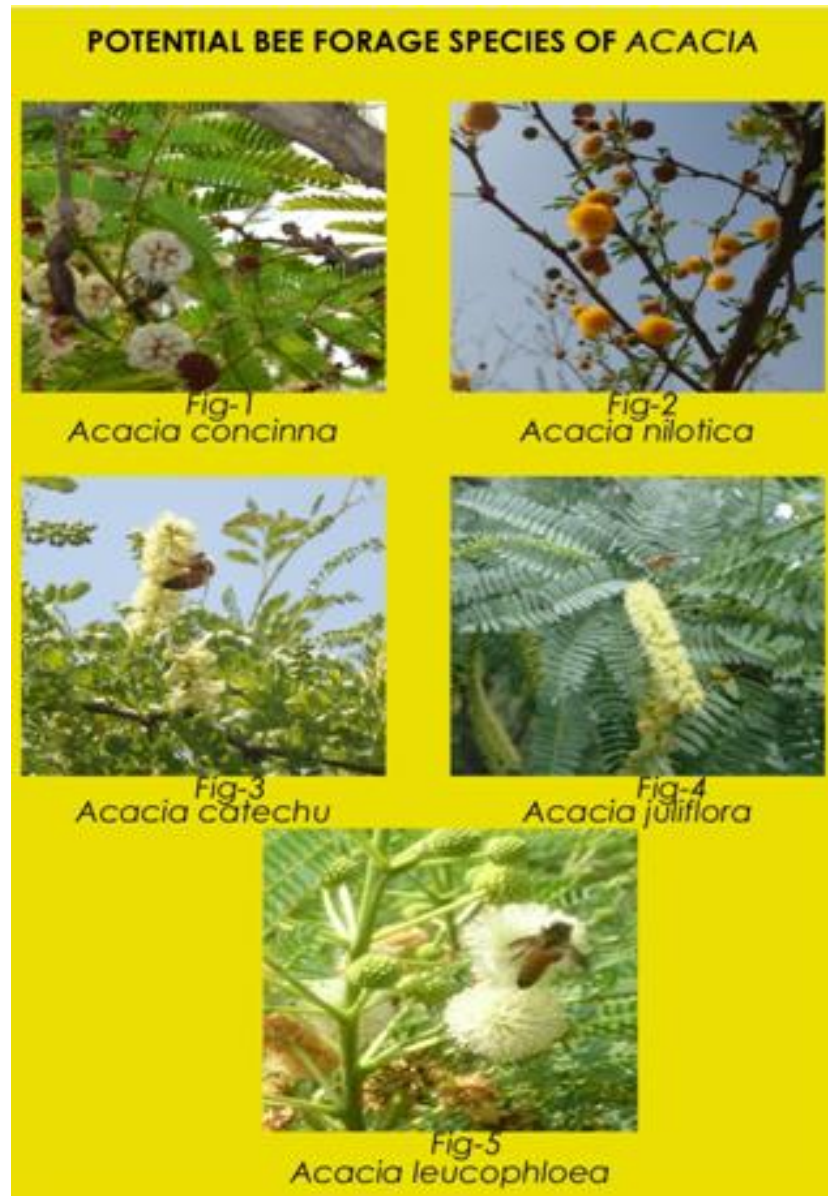

Figures (1-5): Potential Bee Forage species of Acacia

Acacia juliflora (Figure 4) is well adapted to warm and dry climates. It is capable of growing under adverse climatic conditions. The blooming period is between March to middle of May. This is excellent source of nectar. During this period it act as excellent source for nectar and pollen. The worker bee fed for 15- 25 seconds during the course of visit. The maximum activities for the collection of bee forage occurs from 8:00 am to 2:00pm. Acacialeucophloea( Figure 5) is perennial evergreen tree and basically used as fodder, forage and soil improvement. The flowering months are from March to middle of April and excellent source of nectar and pollen. It has been observed that bee worker visits the flowers for 15 to 25 seconds. The activities phase occurs between 7:30 am to 2:00 pm .

\section{Conclusion}

Beekeeping depends on good colony management and good beekeeping areas, and in order to promote it as a profitable agricultural occupation, areas with a good potential for beekeeping must be evaluated.The abundance of bee flora and their continuous availability is one of the major prerequisites for successful beekeeping. This enables the beekeepers to exploit these sources to the maximum utilization by the bees. Every region has its floral dearth phase of short or long duration and it is essential to manage the honey bees and bee hives in the dearth period. As during this period, there is lack of availability of nectar and pollen in flora required for quantitative and qualitative production of honey particularly during June and July . To overcome this problem, it is important to find out the suitable bee flora available in the locality to propagate and manage the plant species to overcome the problem during the dearth period for commercial apiculture. There is a need to prepare a floral inventory for working out the available potential of Acacia in the Chandigarh region would facilitate the workersin the apiculture operation in and around Chandigarh

\section{Acknowledgements}

The authors would like to express sincere thanks to Principal, P.G. Govt. College for Girls, Sector-42, Chandigarh for providing necessary facilitates. We are thankful to Department of Science \&Technology , UT, Chandigarh for providing the financial assistance .

\section{References}

[1] Abrol DP.(1997) Bees and Bee-Keeping in India, Edn1,Kalyani Publishers, New Delhi :110-130.

[2] G.M. Rao( 1991 ) Studies on the floral biology and pollination requirement of scented methi(Trigonellacorniculatalinn.), Indian Bee J 53, : 39-43.

[3] G.M. Rao and M.C. Suryanarayana( 1990) Studies on foraging behaviour of honeybees and its effect on the seed yield in niger, Indian Bee J. 52, : 31-33.

[4] Kohli, R.K., Arya, K.S., Singh, H.P. and Dhillon, H.S.( 1994) . Tree Directory of Chandigarh , Edn1, Lovedale Educational Publishers, New Delhi ,:178-192.

[5] Kumar, D. and Bharti, U. (2015). Tropic Niche Specialization of Butea monosperma from Chandigarh . Journal of Entomology and Zoology Studies; 3(4):8385.

[6] Kumar, D. Sharma, V. and Bharti, U. ( 2015). Mapping of medicinal flora as honey bee forage Journal of Entomology and Zoology Studies, 3(6):235238.

[7] S. Harugade andS.Chaphalkar( 2013 ) Floristic studies with reference to Honey bees of Baramati, Pune District International Journal of Advancements in Research \& Technology, Volume 2, Issue 8:.178-187.

[8] S.S. Darshad, J.K. Sharma and P.R. Yadav ( 1992) foraging speed of insect visitors to the blooms of various cultivars of apple(Malus domesticaBorkh), Indian Bee J. 54, : 92-98.

[9] V.G. Prasad and A. Verghese( 1983) Importance of honeybees in horticultural production, Proc. 2nd Int.Conf.Apic.Trop. Climates, New Delhi, : 590-594 